\title{
UM ITINERÁRIO DE PESQUISA: ASPECTOS SOBRE A TEMÁTICA PATRIMÔNIO HISTÓRICO-EDUCATIVO NA HISTÓRIA DA EDUCAÇÃO (2000-2015) ${ }^{1}$
}

\author{
Maria Teresa Santos Cunha \\ Universidade do Estado de Santa Catarina - UDESC \\ mariatsc@gmail.com \\ Emerson César de Campos \\ Universidade do Estado de Santa Catarina - UDESC \\ ecdcampos@yahoo.com.br
}

\section{RESUMO}

Neste artigo discutimos a presença de temáticas ligadas ao Patrimônio Cultural designado como Patrimônio Histórico-Educativo em suas ocorrências nos Congressos Brasileiros de História da Educação (CBHE), realizados entre 2000 e 2015, em diferentes regiões do país. Embora seja recente a inserção da temática nos Congressos da CBHE, o Patrimônio Histórico-Educativo tem uma historicidade significativa a ser visibilizada, articulada à História da Educação. Para os resultados apresentados, a fonte, em sua parte mais consistente, foi construída a partir do número de trabalhos inscritos nos congressos da CBHE, no período citado, que encerram inserção, desde seus títulos, às temáticas concernentes ao Patrimônio Histórico-Educativo.

Palavras-chave: Patrimônio Histórico-Educativo. História da Educação. Congressos da Sociedade Brasileira de História da Educação.

\section{UN ITINERARIO DE INVESTIGACIÓN: ASPECTOS DEL TEMA PATRIMONIO HISTÓRICO-EDUCATIVO EN LA HISTORIA DE LA EDUCACIÓN (2000-2015)}

\section{RESUMEN}

En este artículo, discutimos la presencia de temas relacionados con el Patrimonio Cultural designados como Patrimonio Histórico-Educativo en sus ocurrencias en los Congresos Brasileños de Historia de la Educación (CBHE), celebrados entre 2000 y 2015, en diferentes regiones del país. Aunque la inserción del tema en los Congresos CBHE es reciente, el Patrimonio HistóricoEducativo tiene una importante historicidad que visualizar, articulado a la Historia de la Educación. Para los resultados presentados, la fuente, en su parte más consistente, se construyó a partir del número de trabajos en los congresos $\mathrm{CBHE}$, en el período citado, cuyas obras indican la inserción, desde sus títulos, en los temas relacionados con el Patrimonio Histórico-Educativo.

Palabras clave: Patrimonio Histórico-Educativo. Historia de la Educación. Congresos de la Sociedad Brasileña de Historia de la Educación.

\footnotetext{
${ }^{1}$ Este texto contou com a colaboração, na pesquisa e na elaboração dos gráficos, das bolsistas de Iniciação Científica do Curso de História (FAED/UDESC - Florianópolis/SC) Flávia de Freitas Souza e Elesiane Bonatto.
} 


\title{
A SEARCH ITINERARY: ASPECTS ON EDUCATIONAL-HISTORICAL HERITAGE THEME IN HISTORY OF EDUCATION (2000-2015)
}

\begin{abstract}
This article discusses emergence of Cultural Heritage or Educational Cultural Heritage theme in its occurrences in History of Education Brazilian Congresses, conducted between 2000 and 2015, in distinct regions of country. Although insertion of theme in these Congresses is recent, Educational Cultural Heritage has a significant historicity to put under a spotlight, which is articulated to History of Education. Presented results' source, in its most consistent part, was made up from registered participants number in Brazilian Congresses of History of Education between 2000 and 2015, whose works belongs to Educational Cultural Heritage, which could be noticed from analyzing their titles.
\end{abstract}

Keywords: Educational-Historical Heritage. History of Education. History of Education Brazilian Society Congresses.

\section{UN ITINÉRAIRE DE RECHERCHE: ASPECTS DU THEME PATRIMOINE HISTORICO-EDUCATIF DANS L'HISTOIRE DE L'EDUCATION (2000-2015)}

\section{RÉSUMÉ}

Dans cet article, nous discutons de la présence de thèmes liés au Patrimoine culturel désigné comme Patrimoine historico-éducatif dans ses occurrences aux Congrès brésiliens d'histoire de l'éducation (CBHE), qui ont eu lieu entre 2000 et 2015, dans différentes régions du pays. Bien que l'insertion du thème aux Congrès de la $\mathrm{CBHE}$ soit récente, le patrimoine historico-éducatif a une historicité importante à visualiser, lorsqu'il est articulé à l'Histoire de l'éducation. Pour les résultats présentés, la source, dans sa partie la plus consistante, a été construite à partir du nombre de participants aux congrès $\mathrm{CBHE}$, dans la période citée, dont les travaux s'insèrent, par leurs titres, dans les thèmes concernant le Patrimoine historico-éducatif.

Mots-clés: Patrimoine historique et éducatif. Histoire de l'éducation. Congrès de la Société brésilienne d'histoire de l'éducation.

\section{INTRODUÇÃO}

Quanto maior a naturalidade com que o narrador renuncia às sutilezas psicológicas, mais facilmente a história se gravará na memória do ouvinte, mais completamente ela se assimilará à sua própria experiência e mais irresistivelmente ele cederá à inclinação de recontá-la um dia. (BENJAMIM, 1994, p. 204). 
Os Congressos Brasileiros de História da Educação (CBHE) são realizados em uma periodicidade de dois anos, desde 2000, como uma das atividades da Sociedade Brasileira de História da Educação (SBHE), fundada em 1999. A partir do material produzido desde 2000 (I CBHE, RJ) e por meio de pesquisa feita nos Anais de cada Congresso, este trabalho pretende apresentar, a partir da realização de um Estado da $\mathrm{Arte}^{2}$, aspectos da produção acadêmica nacional denominada como Patrimônio Cultural ou Patrimônio Histórico Cultural Educativo, produzida nos Congressos da área de História da Educação.

Foram os seguintes os Congresso Brasileiros de História da Educação (CBHE) pesquisados para a realização deste trabalho:

QUADRO 1 - CBHE pesquisados.

\begin{tabular}{|r|l|l|l|}
\hline \multicolumn{1}{|c|}{ Número } & Data & \multicolumn{1}{c|}{ Local } & \multicolumn{1}{c|}{ Tema geral } \\
\hline I CBHE & 2000 & UFRJ/RJ & Educação no Brasil: História e Historiografia \\
\hline II CBHE & 2002 & UFRN/Natal & História e Memória da Educação Brasileira \\
\hline III CBHE & 2004 & PUCPR/Curitiba & A Educação Escolar em Perspectiva Histórica \\
\hline IV CBHE & 2006 & UCG /Goiânia & A Educação e seus sujeitos na História \\
\hline V CBHE & 2008 & UFS/Aracaju & O Ensino e a Pesquisa em História da Educação \\
\hline VI CBHE & 2010 & UFES/Vitória & Invenção, Tradição e Escritas da História da Educação no Brasil \\
\hline VII CBHE & 2013 & UFMT/Cuiabá & Circuitos e Fronteiras da História da Educação no Brasil \\
\hline VIII CBHE & 2015 & UEM/Maringá & História da Educação: matrizes interpretativas e internacionalização \\
\hline
\end{tabular}

Fonte: elaborado pelos autores.

Os motivos mais relevantes que encadeiam este procedimento, chamado de Estado da Arte, ligam-se ao fato de que, na História da Educação, já é perceptível um número considerável de trabalhos que abordam essa temática. As motivações para este texto partiram de uma solicitação feita durante a realização do $1^{\circ}$ Simpósio de Patrimônio Educativo realizado na UNICAMP, em 2012, sob a coordenação da Professora Doutora Maria Cristina Menezes ${ }^{3}$. Naquela oportunidade, houve uma demanda para a realização de um trabalho dessa natureza junto ao material produzido pelos Congressos Brasileiros da História da Educação, como locus preferencial de produção acadêmica da área. Segundo Menezes (2014, p. 225),

\footnotetext{
${ }^{2}$ Estado da Arte é um levantamento criterioso de uma área científica, com a finalidade de evidenciar a produção realizada em uma temática específica.

${ }^{3}$ Maria Cristina Menezes é docente de História da Educação na Universidade de Campinas/SP (UNICAMP), líder do Grupo de Pesquisa CIVILIS e Editora-Geral da R-RIDPHE (Revista Iberoamericana do Patrimônio HistóricoEducativo) que circula desde 2015 e congrega, em artigos, reuniões e eventos, investigadores nacionais e internacionais preocupados com a preservação, a investigação e a difusão do Patrimônio Histórico-Educativo. Disponível em: https://econtents.bc.unicamp.br/inpec/index.php/ridphe/index. Acesso em: 15 set. 2020.
}

Rev. Iberoam. Patrim. Histórico-Educativo, Campinas (SP), v. 6, p. 1-16, e020021, 2020. 
Para ações voltadas à preservação dos itens documentais, buscou-se apoio em outras áreas; a arquivística, a biblioteconomia, e a história da educação, sempre com projetos interdisciplinares, abertos a várias frentes, que se apresentaram para o diálogo. O apoio do AEL, Arquivo Edgard Leuenroth, da UNICAMP, foi importante por nos introduzir nos trabalhos de desinfestação com o nitrogênio. Dessa forma nos preparávamos para desalojar sumariamente os indesejáveis intrusos, pragas já conhecidas dos documentos, como as brocas, traças, cupins, que habitavam os carcomidos suportes documentais. A interlocução com outros pesquisadores, do Brasil e exterior, também foi fundamental, como Rogério Fernandes (Portugal), Augustin Escolano e Antonio Vinão (Espanha), entre outros.

Para a realização deste artigo, não se procuraram raízes e/ou origens em sua forma original, mas como este tema se faz presente na área no sentido de tentar responder às condições particulares e de emergência do contexto em que se encontra. Ainda nesse sentido, considera-se que esses eventos são acontecimentos importantes, pois, geralmente, agenciam encontros, projetos, e fazem circular ideias que colaboram para a implementação e mesmo para a consolidação de um tema e/ou área, como se pode vislumbrar na presença, sempre crescente, dos estudos sobre o Patrimônio Histórico-Educativo nos Congressos promovidos pela Sociedade Brasileira de História da Educação. Não raro, considerado insignificante nas ciências humanas, os estudos de François Dosse (2013) sinalizam para um significado qualificado do acontecimento como um fenômeno singular que pode ser concebido como um "indício significante”, pleno de vestígios que provocam configurações inéditas, pois

Atribuir inteira importância ao vestígio do acontecimento, denotado na evolução flutuante de suas representações e de suas interpretações, significa realizar plenamente a guinada historiográfica que inclui o estudo dos usos e práticas da história no ato de escrever a história. (DOSSE, 2013, p. 213).

Consolidado como acontecimento, nesta perspectiva levantada por Dosse (2013), pode-se considerar que as referências e as pesquisas relacionadas ao binômio Patrimônio Cultural e à Educação, também chamado de Patrimônio Histórico-Educativo, comportam tanto a produção material quanto imaterial da escola como meio para compreender e auxiliar nos processos de reflexão da História no presente. Assim, a temática do patrimônio cultural escolar, dada a ver através do que se convencionou chamar de patrimônio histórico-educativo, pode ser considerada como o resultado de escolhas das práticas culturais representadas na materialidade e na 
imaterialidade de uma sociedade que merecem ser preservadas, notadamente em função de vivermos uma fúria preservacionista que tem gerado uma obsessão pela memória (HUYSSEN, 2000), conforme destaca o autor:

[...] há uma restauração historicizante de velhos centros urbanos, cidades-museus. empreendimentos patrimoniais e heranças nacionais [...] o boom da moda retrô, a comercialização em massa da nostalgia, a obsessiva automusealização através da câmera de vídeo, a literatura memorialística e confessional, [...] uma cultura da memória [...] um desejo de puxar esses vários passados para o presente [...],Enfim, uma obsessão pela memória de proporções monumentais em todo o planeta. (p. 14$18)$.

No âmbito da História da Educação também são muitos os desafios, em particular no ambiente relacionado à cultura material escolar, que se insinuam cada dia mais como lugar de memória, passíveis de patrimonialização. A produção acadêmica sobre a História da Educação, associada aos estudos relacionados à sua materialidade, é algo que tem crescido nos últimos anos a ponto de fazer emergir essa área de estudos denominada de Patrimônio Histórico-Educativo e esse fato tem ampliado "consideravelmente as possibilidades de compreensão dos processos educativos na sociedade brasileira" (POSSAMAI, 2012, p. 116). Segundo a autora, por exemplo, a edificação escolar e os objetos da cultura escolar vinculados ao ensino podem ser considerados como bens de grande relevância e, a partir deles, é possível discutir sobre as apropriações sociais diversas no presente, o que pode motivar a sua preservação.

É importante ressaltar que o patrimônio cultural escolar - também chamado de patrimônio histórico-educativo, o qual pode ser estudado dentro da História da Educação - é uma construção histórica e social, não apenas um conjunto de bens culturais naturalizados como sendo patrimônio de uma coletividade. Nesse sentido, há todo um investimento de estudos patrimoniais ligados à História da Educação que visam a "propor problemáticas a esses bens culturais na perspectiva do conhecimento histórico" (POSSAMAI, 2012, p. 117).

De fato, as duas últimas décadas indicam ampliação significativa da temática em larga medida afinada com sua internacionalização. Essas motivações contribuíram para operacionalizar essa presença na área de História da Educação e o primeiro movimento foi investigar tal presença a partir do número de trabalhos efetivamente apresentados nos Congressos Brasileiros de História da Educação. Ainda que não seja objeto deste artigo, convém salientar que esses estudos têm sido impulsionados, também, pelo grupo CIVILIS/UNICAMP e a RIPDHE, que vêm organizando, 
desde 2012, os Simpósios Iberoamericanos do Patrimônio Histórico-Educativo que são propulsores dos estudos e da divulgação desta temática e que merecerão, posteriormente, estudos mais aprofundados ${ }^{4}$.

Neste itinerário de pesquisa, entretanto, escolhemos por horizonte a realização dos Congressos Brasileiros de História da Educação, entre 2000 e 2015 e, neles, buscou-se investigar a presença de pesquisas nessa temática a partir das abordagens da História do Tempo Presente, inquirindo "como em cada presente, as dimensões temporais do passado e do futuro tinham sido postas em relação" (HARTOG, 2006, p. 262) e entendendo-a na perspectiva dos estudiosos do Instituto da História do Tempo Presente, na França, para quem a configuração deste campo está relacionada tanto a um domínio da historiografia como à sua dimensão temporal não meramente como um marco cronológico, mas especialmente àqueles voltados à memória que, em geral, têm proximidade dos historiadores com seus objetos de estudo, como "um vibrato do inacabado que anima um passado, um presente aliviado de seu autismo, uma inteligibilidade perseguida fora de alamedas percorridas; é um pouco isto a história do presente" (RIOUX, 1999, p. 49-50).

Os estudos relacionados ao Tempo Presente evidenciam o contemporâneo a partir de uma centralidade em duas palavras: memória e patrimônio. Hartog (2006) remete à existência de um dever de memória que condiciona, de certa maneira, uma ânsia de patrimonialização. Este processo custou mais tempo a chegar à área da História da Educação, possivelmente por ter ela uma tradição de trabalhar com grandes temas tradicionalmente centrados no estudo das legislações educacionais, das reformas de ensino e da história do pensamento ou da filosofia da educação. Entretanto, dentro desses mesmos temas, começaram a emergir objetos da cultura material escolar (prédio escolar/os utensílios escolares, arquivos escolares e de educadores/as etc.) capazes de guardar os traços do vivido e que passaram a ser estudados pela via da cultura material da escola. Sendo assim,

A nova configuração do campo do patrimônio no Brasil, redesenhada nas duas últimas décadas, abrange uma multiplicidade de dimensões como o patrimônio tangível e intangível, o natural e o genético. Os grandes temas em debate nesse campo atualmente são as tensões entre o particular e o universal, o público e o privado, os desafios postos pelo patrimônio imaterial, a necessidade de uma política nacional de acervos digitais para a democratização da informação, o papel da educação patrimonial, a garantia de efetividade das políticas de preservação e a banalização do patrimônio histórico pela conversão de seu valor de uso em valor

\footnotetext{
${ }^{4}$ No Brasil, sob Coordenação da Prof. ${ }^{a}$ Dr. ${ }^{a}$ Maria Cristina Menezes (UNICAMP) até o presente momento, foram realizados 7 (sete) simpósios: 2012 (Unicamp/SP); 2013 (Argentina); 2014 (México); 2015 (Centro Paula Souza e Unicamp/SP); 2016 (San Sebastian/Espanha); 2017 (Unicamp/SP) e 2019 (Berlanga de Duero/Espanha).
} 
econômico e as consequências de sua exploração pelo turismo e pela indústria cultural, indiferente ao desenvolvimento sustentável. (SOUZA, 2013, p. 203).

Essas pesquisas e apontamentos foram fortificados nas duas primeiras décadas do século XXI, cujas iniciativas indicam uma consolidação da área como campo de pesquisas e estudos e foi um dos motes para a realização deste levantamento, em especial para uma revista como essa que invoca, desde seu título, a condição de rede ibero-americana de difusão do patrimônio histórico e educativo.

\section{COMPARTILHANDO EXPERIENCIAS: $O$ LEVANTAMENTO $\quad$ E SEUS PROCEDIMENTOS}

Para a realização deste estudo/levantamento, foi necessário traçar uma estratégia de busca, identificação e categorização dos textos e resumos dos trabalhos de pesquisa centrados no material produzido pelos Congressos Brasileiros de Educação no período entre 2000 e 2015. Este material, mais especificamente por meio digital ${ }^{5}$, serviu de ferramenta para identificação, nos trabalhos publicados, de temáticas ligadas ao Patrimônio.

Inicialmente, foi utilizado um método de verificação dos trabalhos publicados, por meio do uso de palavras-chaves que remetessem à temática "Patrimônio Cultural", "Escolar" ou "Educativo" nos trabalhos publicados. O objetivo era lançar mão de termos usualmente utilizados para tratar o assunto ou que designassem instituições ligadas ao tema ("Cultura Material Escolar", "Patrimônio Educativo", “Objetos da Escola”, "Museus da Educação”, "Museu Pedagógico", "Museu Escolar", “Centro de Documentação”, “Arquivos Escolares” etc.).

Nesse estágio, apresentaram-se as primeiras dificuldades: a mais notável foi uma quase ausência da própria palavra "patrimônio", tanto nas temáticas gerais dos congressos, como nos títulos e nas palavras-chaves selecionadas pelos próprios autores dos trabalhos para evidenciar os temas centrais abordados em suas pesquisas.

Ainda que o termo não aparecesse nos títulos, nas palavras-chaves ou no próprio corpo do resumo, era perceptível a intenção do autor, ainda que superficialmente, de abordar a temática, no

\footnotetext{
${ }^{5}$ Foram consultados os CDs dos eventos que fazem parte dos acervos pessoais dos autores. Também podem ser encontrados em http://www.sbhe.org.br/. Os anos de 2017 e 2019 não fazem parte da amostra investigada. Até o fechamento deste artigo, não foi possível acessar os dados de 2017. Dessa forma, mesmo de posse dos dados de 2019, para evitar desvios que eventualmente comprometessem a pesquisa, decidimos não os considerar.
} 
entanto, muitos textos ainda se apresentavam bastante descritivos, com pouca elaboração teórica que se conectasse com a área específica dos estudos de Patrimônio com sua vinculação à História.

O levantamento permitiu considerar a existência de uma possível mudança quanto à abordagem de determinados temas e à utilização de termos, mais especificamente, aqueles que remetessem a "Patrimônio Escolar". No campo da História da Educação, como já abordado anteriormente, os grandes temas, como instituições escolares, formação de professores e legislação educacional, ainda que despertassem interesse de estudo, foram dando espaço a outros temas, situação observada por Lopes e Galvão (2001, p. 40) que indicam

[...] uma verdadeira revolução na seleção dos objetos de pesquisa e na forma de abordá-los. Temas como a cultura e o cotidiano escolares, a organização e o funcionamento das escolas, a construção do conhecimento escolar, o currículo e as disciplinas, os agentes educacionais (professores, professoras, mas também alunos e alunas), a imprensa pedagógica, os livros didáticos etc., têm sido crescentemente estudados e valorizados.

A pesquisa foi mostrando que somente a partir do Congresso de 2008 (Aracaju) esse quadro foi sendo alterado, quando se estabeleceu, pela primeira vez, no âmbito do evento, um eixo temático específico para tratar do tema "Patrimônio na História da Educação".

Solucionada a dúvida inicial, a proposta envolveu uma ampliação nos termos e critérios de pesquisa, especialmente a utilização de palavras descritoras mais específicas ao tema (“Cadernos Escolares”, “Cultura Escrita”, “Arquivos Escolares”, “Cultura Material Escolar”, "Museus Escolares" etc.), e a observação da relevância dos autores e suas respectivas instituições. Pode-se considerar que a metodologia foi utilizada com sucesso, pois permitiu maior agilidade nas buscas.

A seguir, no Quadro 2, coloca-se apenas um exemplo de tabela que foi preenchida para fazer o levantamento de dados, salientando-se que a quantidade de trabalhos neste evento (em número de 40) não continham, de forma geral, patrimônio histórico-educativo como palavrachave. 
QUADRO 2 - Exemplo de levantamento de dados.

\begin{tabular}{|c|c|c|c|c|}
\hline \multicolumn{5}{|c|}{ V CONGRESSO BRASILEIRO DE HISTÓRIA DA EDUCAÇÃO - 2008 - Aracaju/SE } \\
\hline Título & Autor & Instituição & Período & Palavras-chave \\
\hline $\begin{array}{l}\text { Os instrumentos científicos como } \\
\text { fontes para a história do ensino } \\
\text { de Ciências e de Física na } \\
\text { educação secundária }\end{array}$ & Rosa Fátima de Souza & $\begin{array}{l}\text { Universidade } \\
\text { Estadual } \\
\text { Paulista }\end{array}$ & $\begin{array}{c}\text { década de } \\
1950\end{array}$ & $\begin{array}{l}\text { História do ensino; } \\
\text { Cultura material escolar; } \\
\text { Instrumentos científicos }\end{array}$ \\
\hline $\begin{array}{l}\text { A ação de preservação de fontes } \\
\text { para a história e a memória da } \\
\text { Educação do sudoeste da Bahia }\end{array}$ & $\begin{array}{l}\text { Ana Palmira B. Santos } \\
\text { Casimiro } \\
\text { Lívia Diana Rocha } \\
\text { Magalhães } \\
\text { Ruy Hermann de Araújo } \\
\text { Medeiros }\end{array}$ & $\begin{array}{l}\text { Universidade } \\
\text { Estadual do } \\
\text { Sudoeste da } \\
\text { Bahia }\end{array}$ & Séc. XX & $\begin{array}{l}\text { Museu Pedagógico; } \\
\text { Arquivos Escolares; } \\
\text { História da Educação; } \\
\text { Memória }\end{array}$ \\
\hline $\begin{array}{l}\text { Brinquedos da minha infância: } \\
\text { socialização de um acervo }\end{array}$ & $\begin{array}{l}\text { Vera Lucia Gaspar da } \\
\text { Silva } \\
\text { Marília Gabriela Petry }\end{array}$ & UDESC & $\begin{array}{c}1800- \\
1990\end{array}$ & $\begin{array}{l}\text { Cultura Material da Escola; } \\
\text { Patrimônio Educativo; } \\
\text { Museu da Escola } \\
\text { Catarinense }\end{array}$ \\
\hline $\begin{array}{l}\text { Das mãos para as mentes: } \\
\text { protocolos de civilidade em } \\
\text { manuscritos escolares (1946-56) }\end{array}$ & $\begin{array}{l}\text { Maria Teresa Santos } \\
\text { Cunha }\end{array}$ & UDESC & $\begin{array}{c}1946- \\
1952\end{array}$ & $\begin{array}{l}\text { Jornal Escolar; } \\
\text { Patrimônio Educativo; } \\
\text { Arquivos escolares }\end{array}$ \\
\hline
\end{tabular}

Fonte: elaborado pelos autores a partir de dados do CD do V Congresso Brasileiro de História da Educação (CBHE) em Aracaju/SE - 2008.

Em um segundo estágio da pesquisa, constatou-se que, após a criação do eixo temático "Patrimônio na História da Educação", houve um significativo aumento na produção de trabalhos tratando especificamente do tema, principalmente nos três últimos Congressos (2011, 2013 e 2013), o que tornou possível considerar uma aparente valorização e necessidade de preservação de memória, provocada por um "presente inquieto, em busca de raízes, obcecado com a memória" (HARTOG, 2006, p. 270). Pode-se conjecturar que, no ano de 2008, correspondente ao V Congresso Brasileiro de História da Educação, houve um maior número de trabalhos em virtude de congregar, em Aracaju, um número expressivo de pesquisadores de várias regiões do país, ligados a um Projeto Nacional sobre a Escola Primária no Brasil ${ }^{6}$ que abrigava um eixo temático destinado a essas questões, o que incrementou produções significativas na temática ${ }^{7}$.

Outra possibilidade que aqui se registra, apenas, foi a iniciativa do GT História da Educação da ANPED (Associação Nacional de Pesquisa e Pós-Graduação em Educação) ter

\footnotetext{
${ }^{6}$ Coordenado pela Prof. ${ }^{a}$ Dr. ${ }^{\text {a }}$ Rosa Fátima de Souza/UNESP - Araraquara/SP, cujos resultados estão sintetizados em livro organizado pela autora - História da Escola Primária no Brasil - citado nas referências (SOUZA; PINHEIRO; LOPES, 2015).

${ }^{7}$ Muitos estudos foram feitos a partir desse projeto nacional. Destacamos a publicação organizada pelo Prof. Dr. César Augusto Castro (2011), intitulada Cultura Material escolar: a escola e seus artefatos (MA, SP, PR, SC e RS-18701925), e o livro Objetos da Escola. Espaços e lugares de constituição de uma cultura material escolar(Santa Catarina - Séculos XIX e XX), organizado pela Prof ${ }^{a}$ Dra. Vera Lucia Gaspar da Silva e Prof. Msc. Marília Gabriela Petry (2012), cujos textos já tangenciavam a questão do Patrimônio Histórico-Educativo.
}

Rev. Iberoam. Patrim. Histórico-Educativo, Campinas (SP), v. 6, p. 1-16, e020021, 2020. 
divulgado, também, em 2009, como seu tema gerador, as questões relativas a Patrimônio e Arquivos Escolares.

Os dados coletados nos CDs foram organizados e classificados por congresso, ano de publicação, autor, instituição e palavras-chaves. Elaborou-se uma tabela na qual as informações foram processadas, com o objetivo de evidenciar a transformação numérica que desencadeou o aumento da quantidade de trabalhos envolvendo os temas ligados ao patrimônio históricoeducativo. Para este momento inicial de pesquisa, optou-se por não destacar autores, pois esse investimento demandaria mais tempo e cuidado. Essa opção, entretanto, não deixou de perceber que houve manutenção do uso da temática em pesquisas ao longo dos congressos.

FIGURA 1 - Gráfico da Temática Patrimônio nos Congressos entre 2000 e 2015.

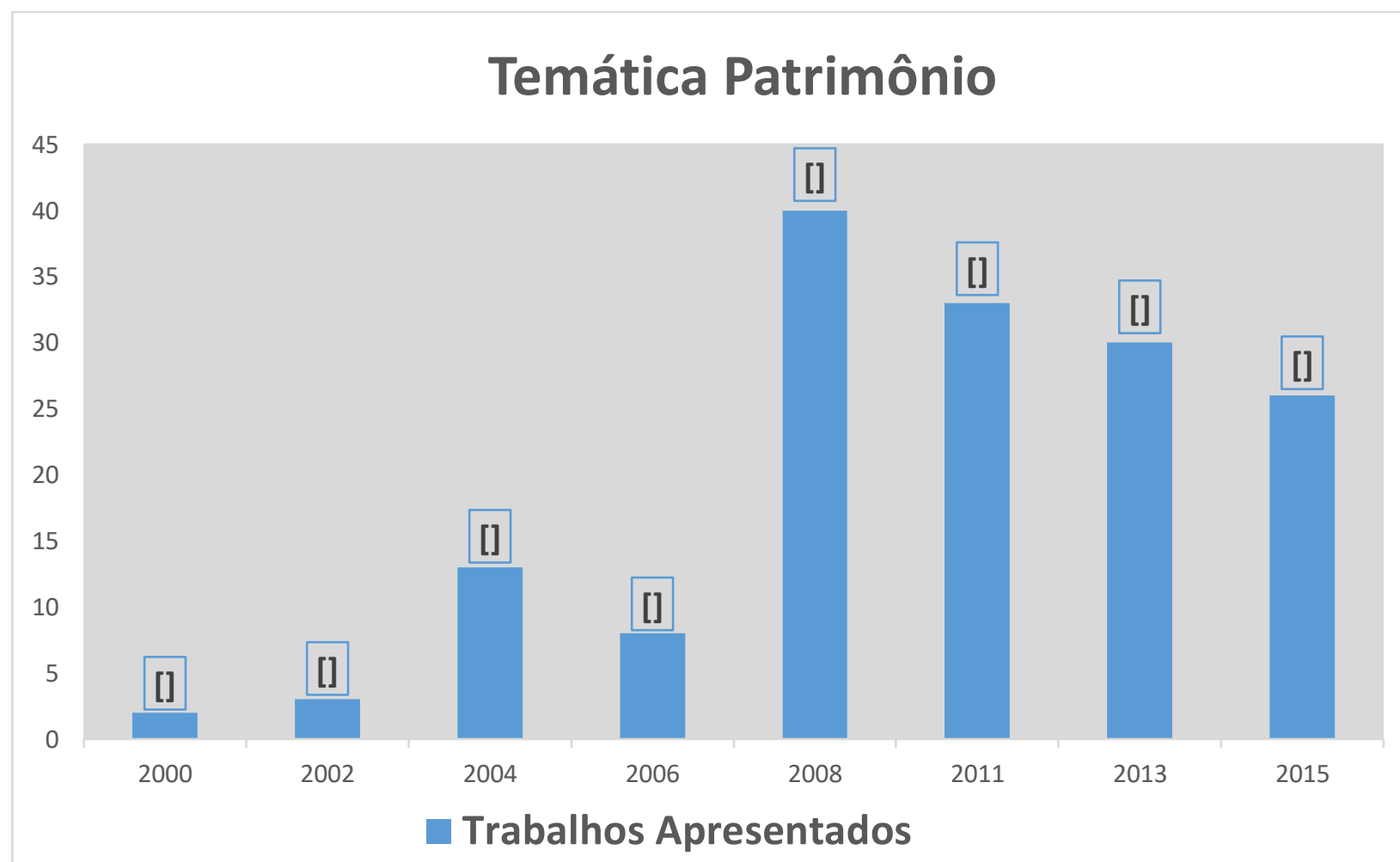

Fonte: elaborado pelos autores a partir de dados dos CDs dos Congressos Brasileiros da História da Educação (2000 - 2015).

O levantamento também permitiu o desenvolvimento de algumas reflexões sobre o recorte temporal e a escolha dos objetos de pesquisa selecionados pelos autores para representar a categoria Patrimônio que esses pretendiam atingir ao tratar do tema na História da Educação brasileira. Nesse 
campo específico, encontram-se pesquisas sobre arquitetura escolar, cultura material da escola, bibliotecas escolares, arquivos institucionais (escolares) e pessoais (de educadores e educadoras), hemerotecas digitais, colecionismo, entre outros. Do total de 155 trabalhos coletados, selecionamos 100 deles, o que significa 64,5\% do total, observando critério de ter a palavra patrimônio (no título ou como uma das palavras-chave).

QUADRO 3 - Trabalhos por Congresso.

\begin{tabular}{|l|c|c|c|c|}
\hline Número & Data & Local & Número de Trabalhos & Trabalhos Pesquisados \\
\hline I CBHE & 2000 & UFRJ/RJ & 02 & 02 \\
\hline II CBHE & 2002 & UFRN/Natal & 03 & 03 \\
\hline III CBHE & 2004 & PUCPR/Curitiba & 13 & 08 \\
\hline IV CBHE & 2006 & UCG /Goiânia & 08 & 04 \\
\hline V CBHE & 2008 & UFS/Aracaju & 40 & 24 \\
\hline VI CBHE & 2010 & UFES/Vitória & 33 & 20 \\
\hline VII CBHE & 2013 & UFMT/Cuiabá & 30 & 21 \\
\hline VIII BHE & 2015 & UEM/Maringá & 26 & 18 \\
\hline TOTAL & - & - & $\mathbf{1 5 5}$ & $\mathbf{1 0 0}$ \\
\hline
\end{tabular}

Fonte: elaborado pelos autores.

FIGURA 2 - Recorte temporal das pesquisas.

\section{Recorte Temporal das Pesquisas}

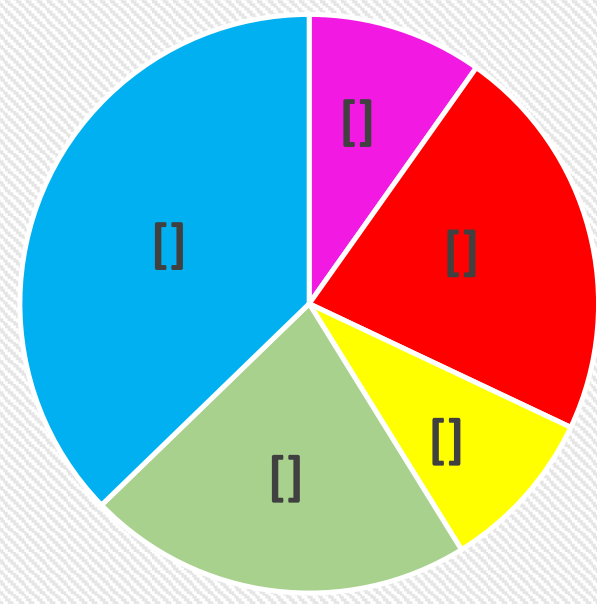

- Século XIX

- Final do Século XIX e início XX

Século XIX e decorrer do XX

Século XX

- Década de 1930 à atual

Fonte: elaborado pelos autores a partir de dados dos CDs dos Congressos Brasileiros da História da Educação (2000 - 2015). 
Sobre o recorte temporal dos trabalhos junto aos Congressos Brasileiros de História da Educação (CBHE), o gráfico elaborado aponta para uma incidência maior de produção de trabalhos a partir do final da década de $1930^{8}$ em diante, fato que permite supor que, a partir desse período, houve uma presença maior de novos objetos na escola, proporcionados pelas abordagens da escola nova, centrada mais no aluno e nas suas atividades (Ensino Intuitivo ou Lições de Coisas), baseado em método utilizado por Norman Calkins e que "obedecia uma sequência de procedimentos que, partindo sempre de um objeto, ascendia à abstração" (VALDEMARIN, 2004, p. 4) e representaram um marco na História da Educação.

Os novos objetos escolares, além de representarem suas múltiplas materialidades, funcionalidades e utilização de forma protocolar, estabelecem uma ligação emblemática entre a escola e o aluno, permitindo ao pesquisador adentrar no campo de apropriações e criação, abrindo espaço à memória pessoal e familiar, aos arquivos pessoais de educadores e educadoras, aos arquivos escolares depositados em instituições de ensino, temas concernentes às abordagens do patrimônio histórico-educativo.

O aumento gradativo de trabalhos com a temática sinaliza para a necessidade e até um certo furor de conservar, catalogar e salvaguardar o patrimônio histórico educativo que remete a uma cultura da memória e representa, de alguma maneira, expectativas e mentalidades coletivas das sociedades escolarizadas. Como tal, são depositários de coisas relevantes do passado formativo comum de algumas gerações e de sua relação com o mundo da escola. De forma pedagógica, o tema convida a uma viagem que nos ajuda a conhecer aspectos da questão patrimonial no âmbito da História da Educação.

\section{ALGUMAS CONSIDERAÇÕES}

A realização do trabalho envolveu um levantamento inicial que recobriu temas, períodos, produtos que, analisados, no Tempo Presente, permitiram uma aproximação a um desenho mais geral da recente historiografia da Educação brasileira que aborda a temática de Patrimônio Cultural,

\footnotetext{
${ }^{8}$ Importante lembrar que é também a partir da década de 1930 que o patrimônio passa a ser sistematizado pelo Estado brasileiro, sendo uma expressão significativa disso a criação do Iphan (Instituto do Patrimônio Histórico e Artístico Nacional) pelo Decreto-Lei $\mathrm{n}^{\circ}$ 25, de 30 de novembro de 1937, que organiza a proteção do Patrimônio Histórico e Artístico Nacional, estabelecendo os bens que o constituem.
} 
Histórico-Educativo, aqui muito entrelaçada à pesquisa com elementos museáveis guardados nos museus e arquivos escolares, como sinalizou Rogério Fernandes (2005, p. 23):

Todos estes objetos (que constituem um patrimônio histórico educativo) são equipamentos que orquestraram composições do ensino e da aprendizagem, tais como livros didáticos, manuais, quadros parietais, registros administrativos, materiais escolares, etc.

$\mathrm{O}$ ainda pequeno esforço interpretativo sinalizou para presenças de temas e objetos, mas também para lacunas e pontos pouco iluminados que poderão apontar possibilidades futuras de investimento acadêmico na área, quando da continuação do trabalho que pretende prosseguir com a análise mais aprofundada, tanto das temáticas como dos autores. Pode-se considerar, igualmente, que as abordagens relacionadas ao Patrimônio Histórico-Educativo construídas junto à História da Educação constituem uma força motriz para o desenvolvimento e a transformação dos indivíduos e da comunidade em que se inserem e que implicam em ações sociais para produção de novos saberes/fazeres, além de compartilhar experiências.

Ainda nesse sentido, podemos inferir, sabedores que somos das apresentações realizadas em 2019 (foram cerca de dezenove apresentações) e da impossibilidade de acesso aos dados de 2017 até o fechamento deste artigo, que o tema investigado, Patrimônio Histórico-Educativo, se insinua de forma significativa na História da Educação, indicando, também, ser um tema prolífico ligado à memória e de capacidade inspiradora a outras áreas correlatas ou até mesmo tangenciais. Este enfoque evidencia uma certa vontade de lembrar sem deixar de considerar que elas podem ser, igualmente, memórias imaginadas, mais suscetíveis ao esquecimento e menos patrimonializada, (HUYSSEM, 2000, p. 18).

O estudo, ainda que inicial, evidenciou que o tempo presente, ou seja, a nossa contemporaneidade, experimenta uma ampliação de pesquisas de cunho histórico na temática, nos quais é observado um crescente movimento de constituição de arquivos por parte de pesquisadores que procuram preservar e analisar, na clave dos estudos de História da Educação, a progressiva presença que a temática Patrimônio Histórico-Educativo tem assumido a partir de diferenciadas formas abordagens e problematizações.

$\mathrm{Na}$ expressão "Tempo Presente", a atenção, tanto de profissionais quanto do público não especializado, é normalmente direcionada para a palavra "presente". Segundo François Hartog (201, as reflexões em torno da temporalidade passaram a ocupar um lugar de destaque nas 
pesquisas historiográficas, em particular nas três últimas décadas (precisamente onde se concentra o período de investigação deste artigo). O presentismo que podemos encontrar referenciado na obra deste historiador francês, resulta de investigação dos diferentes regimes de historicidade, e se apresenta como um decifrar possível sobre certos fenômenos do presente, ou seja, significa os diferentes e imprecisos modos pelos quais a sociedade contemporânea configura e apresenta sua experiência temporal. Assim, temos a contínua e necessária problematização do que chamamos (ainda que provisoriamente) de presentismo. Nesse presente alargado, em que o passado não para de acontecer (ROUSSO, 2016), a (i)materialidade do Patrimônio Histórico-Educativo certamente está articulada - de modo colaborativo - à complexificação do Tempo Presente e a emergência desse campo aqui insinuado bem mostra isso.

Tentamos mostrar que existe uma prosperidade de sentidos relacionados ao Patrimônio Histórico-Educativo e a complexidade desse campo, dinâmico em sua contemporaneidade. Temos, ainda, que ressaltar as possibilidades de atuação profissional e/ou renovação das perspectivas de investigação e intervenção na área, o campo do patrimônio tem atraído especialistas, acadêmicos, estudantes e movimentos sociais e culturais. É o que, entre outros, nos indica Nogueira (2014, p. 46) quando afirma que,

No Brasil, independentemente das temáticas e escalas que refletem as experiências locais, regionais e nacionais, sem perder de vista sua inserção em termos globais, os processos de patrimonialização de bens e práticas culturais, ao mesmo tempo em que sinalizam os deslocamentos conceituais da memória e do patrimônio, colocam a necessidade de refletir sobre a historicidade mesma de tais conceitos e das práticas preservacionistas a eles relacionadas em sintonia com o desafio da interdisciplinaridade.

Por último, e aqui nesta oportunidade, indicamos que os apontamentos realizados a partir destes estudos, ainda que iniciais, sobre o Patrimônio Histórico-Educativo e ligados àqueles apresentados nos Congressos Brasileiros de História da Educação no mapeamento apresentado neste momento (2020), nos indicaram a possibilidade de identificar sua presença e memória, não atendendo a fins laudatórios, mas na busca da compreensão de seus sentidos no presente e em seus questionamentos na contemporaneidade. Para se impor como tema, as questões relativas ao Patrimônio Histórico-Educativo dependem tanto do aumento de estudos e pesquisas como "de reflexão erudita, vontade política e de reconhecimento documental e sentimental" (POULOT, 2009, p. 13). 


\section{REFERÊNCIAS}

BENJAMIM, Walter. Magia e técnica, arte e política: ensaios sobre literatura e história da cultura. Tradução de Sergio Paulo Rouanet e Prefácio de Jeanne Marie Gagnebin. São Paulo: Brasiliense, 1994.

BRASIL. Casa Civil. Decreto-Lei no 25, de 30 de novembro de 1937. Organiza a proteção do patrimônio histórico e artístico nacional. Diário Oficial da República, Rio de Janeiro, 1937. Disponível em: http://bit.ly/30nuxvg. Acesso em: 24 set. 2020.

CASTRO, César Augusto (Org.). Cultura material escolar: a escola e seus artefatos (MA, SP, PR, SC e RS, 1870-1925). São Luís: EDUFMA: Café \& Lápis, 2011.

DOSSE, François. Renascimento do acontecimento: um desafio para o historiador: entre Esfinge e Fênix. Tradução de Constancia Morel. São Paulo: UNESP, 2013.

FERNANDES, Rogério. Cultura da escola: entre as coisas e as memórias. Pro-Posições, Unicamp, Campinas, SP, v. 16, p. 19-39, jan./abr. 2005. (Dossiê cultura escolar e cultura material escolar: entre arquivos e museus).

HARTOG, François. Tempo e patrimônio. Revista Varia História, Belo Horizonte, v. 22, n. 36, p. 261-273, jul./dez. 2006.

HARTOG, François. Regimes de historicidade. Presentismo e experiências do tempo. Tradução de Andréa S. de Menezes, Bruna Beffart, Camila R. Moraes, Maria Cristina de A. Silva e Maria Helena Martins. Belo Horizonte: Autêntica, 2013.

HUYSSEN, Andreas. Seduzidos pela memória: arquitetura, monumentos, mídia. 2. ed. Rio de Janeiro: Aeroplano, 2000.

LOPES, Eliane Marta Teixeira; GALVÃO, Ana Maria de Oliveira. História da educação. Rio de Janeiro: DP\&A, 2001.

MENEZES, Maria Cristina. Entrevista: Entre porões e sótãos: o patrimônio histórico-educativo em cena. Revista Linhas, Florianópolis, v. 15, n. 28, p. 223-249, jan./jun. 2014. Disponível em: https://bit.ly/2RRHThf. Acesso em: 24 set. 2020.

NOGUEIRA, Antonio Gilberto Ramos. O campo do patrimônio cultural e a história: itinerários conceituais e práticas de preservação. Revista Antítese, v. 7, n. 14, p. 45-67, jul./dez. 2014.

POSSAMAI, Zita Rosane. Patrimônio e história da educação: aproximações e possibilidades de pesquisa. Revista História da Educação, v. 16, n. 36, p. 110-120, 2012.

POULOT, Dominique. Uma história do patrimônio no Ocidente. Tradução de Guilherme João de Freitas Teixeira. São Paulo: Estação Liberdade, 2009. 
RIOUX, Jean-Pierre. Pode-se fazer uma história do presente? In: CHAVEAU, Agnes; TÉTARD, Philippe (Orgs.). Questões para a história do tempo presente. Tradução de Ilka Stern Cohen. Bauru: EDUSC, 1999. p. 39-40.

ROUSSO, Henry. A última catástrofe: a história, o presente, o contemporâneo. Tradução de Fernando Coelho e Fabrício Coelho. Rio de Janeiro: FGV, 2016.

SILVA, Vera Lucia Gaspar da; PETRY, Marília Gabriela (Orgs.). Objetos da Escola. Espaços e lugares de constituição de uma cultura material escolar (Santa Catarina - Séculos XIX e XX). Florianópolis: Insular, 2012.

SOUZA, Rosa Fátima de. Preservação do patrimônio histórico escolar no Brasil: notas para um debate. Revista Linhas, Florianópolis, v. 14, n. 26, p. 199-221, jan./jun. 2013.

SOUZA, Rosa Fátima de; PINHEIRO, Antonio Carlos Ferreira; LOPES, Antônio de Pádua Carvalho (Orgs.). História da escola primária no Brasil: investigação em perspectiva comparada em âmbito nacional. Aracaju: Edise, 2015.

VALDEMARIN, Vera Teresa. Estudando a lição de coisas: análise dos fundamentos filosóficos do Método de Ensino Intuitivo. Campinas, SP: Autores Associados, 2004.

Recebido em: 24 de setembro de 2020 Aceito em: 12 de novembro de 2020 